\title{
EL ABSURDO DE MI MUERTE COMO ALIENACIÓN PERMANENTE DE MI SER-POSIBLE*
}

Bernard Schumacher**

\section{Tras las críticas formuladas por}

Sternberger y Landsberg en los años treinta, contra la solución heideggeriana del ser-hacia-la-muerte y antes de aquéllas que fueron desarrolladas por Lévinas, Derrida y Macho, ${ }^{1}$ en los últimos años, para citar solamente algunas, Sartre es el primer filósofo renombrado que, al mismo tiempo que propone una ontología distinta de la de Heidegger, elabora una concepción propia de la muerte, en oposición al ser-hacia-la-muerte heideggeriano, que describe en L'Être et le Néant como un 'pase de magia'. ${ }^{2} \mathrm{Su}$ meta principal no reside

* Traducción de Silvia Pasternac.

** Universidad de Friburgo.

${ }^{1}$ Ver Dolf Sternberger, "Der verstandene Tod. Eine Untersuchung zu Martin Heideggers Existenzial-Ontologie", en Über den Tod, Schriften I, 1977, Frankfurt am Main, Insel Verlag, p. 69-264. Paul-Louis Landsberg, Essai sur l'expérience de la mort, 1951, 1993, París, Seuil. [En español: Ensayo sobre la experiencia de la muerte: el problema moral del suicidio, 1995, Madrid, Caparrós, 171 p.] Emmanuel Lévinas, La mort et le temps [La muerte y el tiempo], París, L'Herne, 1991. Jacques Derrida, Apories. Mourir - s'attendre aux 'limites de la vérité', 1996, París, Galilée. [En español: Aporías. Morir-esperarse (en) los límites de la verdad, Barcelona, Paidós, traducción de Cristina de Peretti, 130 p.] Thomas Macho, Todesmetaphern, 1987, Frankfurt am Main, Suhrkamp.

${ }^{2}$ Ver Jean-Paul Sartre, L'Être et le Néant. Essai d'ontologie phénoménologique, 1943, París, Gallimard, p. 617. [En español: Jean-Paul Sartre, El ser y la nada, 2004, Buenos Aires, 
en un estudio 'exhaustivo' y 'detallado'3 de la muerte, sino en una clarificación del ser-en-situación. Construye su tanatología sobre su ontología de la libertad y su antropología del ser-para-el-otro, donde la relación entre los para-sí es del orden del conflicto: la meta del ser-para-el-otro consiste en reducir al otro a un en-sí. Según Sartre, yo no estoy en condiciones de esperar 'mi muerte', la muerte no es una posibilidad insigne e intrínseca al para-sí, y no le da sentido a la existencia del para-sí libre. La muerte es extrínseca a la vida. Nadiza el sentido de la proyección libre de los posibles del para-sí que en definitiva, una vez muerto, es reducido a un en-sí, y el sentido de sus acciones pasadas es, a partir de ese momento, concedido por el parasí sobreviviente. Mi muerte es absurda. Por otro lado, el otro me es indispensable para alcanzar la conciencia de mi mortalidad. Aunque reconoce ciertamente, con Heidegger, y siguiendo a Epicuro, que no existe experiencia de la muerte propiamente hablando (comprendida como estado de muerte), Sartre sostiene, contra Heidegger y Scheler, que sólo el rodeo por la experiencia de la muerte del otro y por la del duelo permite reconocerse como mortal. La reflexión sartriana representa una piedra angular del debate sobre la muerte y el sentido

64 de la vida que marcó la primera parte del siglo Xx; parece anunciar la actual discusión, en el seno de la tradición analítica, alrededor del sentido de la vida y del estatuto de mal atribuido a la muerte: ${ }^{4}$ dicho estatuto vendría del hecho de que ella priva al sujeto de posibles, interrumpiendo la proyección de sus libres proyectos por-venir. La posición sartriana se cuenta entre las proposiciones tanatológicas más originales del siglo XX, pero no recibió el crédito que merecía, $\mathrm{y}$

Losada.] Derrida describe la tesis del ser-hacia-la-muerte, esta posibilidad de la imposibilidad, como una aporía (Apories, p. 172), y Adorno, como tautología (Jargon der Eigentlichkeit, $1977^{8}$, Frankfurt am Main, Suhrkamp, p. 108).

${ }^{3}$ Ver Jean-Paul Sartre, L'Être et le Néant, p. 633. Ver también con respecto a las experiencias de Sartre de la muerte durante su infancia y su juventud, Les Mots, 1994, París, Gallimard. [En español: Jean-Paul Sartre, Las Palabras, 1964, Buenos Aires, Losada, traducción de Manuel Lamana.]

${ }^{4}$ Ver Bernard N. Schumacher, "De la indiferencia de la muerte a la muerte como un mal”, Revista de Filosofia Iberoamericana, primavera de 2007. 
demasiado a menudo se la ha presentado sólo a grandes rasgos. ${ }^{5} \mathrm{Me}$ propongo analizar paso a paso el procedimiento desarrollado por Sartre en L'Etre et le Néant, y cuestionar específicamente la corrección de su interpretación del ser-hacia-la-muerte heideggeriano. Discutiré así, en primer lugar, las concepciones realista e idealista de la muerte; en segundo lugar, la posibilidad de una espera de 'mi' muerte; en tercer lugar, la muerte en relación con la teoría sartriana de la significación; finalmente, la concepción de la muerte como una victoria del otro y como una situación-límite.

\section{Las concepciones realista e idealista de la muerte}

En L'Être et le Néant, Sartre distingue dos concepciones de la muerte con la ayuda de una doble significación de la palabra 'término'. La muerte se puede comprender, primero, como un término "que se adhiere a la nada del ser que limita el proceso considerado". ${ }^{6}$ Por ser lo que hay del otro lado del 'muro', consiste en un acontecimiento que se sitúa fuera de la vida. Se la considera como 'lo inhumano por excelencia', 7 que abre sobre la nada de lo viviente. Esta concepción, llamada realista, concibe a la muerte como el estado de muerte que excluye toda simultaneidad con la vida, como un 'trascendente a la vida'. ${ }^{8}$ Es el 'gran inconocible' 9 que limita a lo humano; es la 'puerta

${ }^{5}$ Ver, por ejemplo, James P. Carse, Death and Existence. A Conceptual History of Human Mortality, 1980, New York, John Wiley and Sons, p. 361 s. Jacques Choron, La mort et la pensée occidentale [La muerte y el pensamiento occidental], 1969, París, Payot, trad. del inglés al francés por M. Manin, p. 210 s. [Texto original: Jacques Choron, Death and Western Thought, 1963, New York, Collier Books.] Alexander Lohner, Der Tod im Existentialismus. Eine Analyse der fundamentaltheologischen, philosophischen und ethischen Implikationen, 1997, Paderborn, Ferdinand Schöningh, p. 186 s. Georg Scherer, Das Problem des Todes in der Philosophie, 1979, Darmstadt, Wissenschaftliche Buchgesellschaft, 1988², p. 170 s.

${ }^{6}$ Jean-Paul Sartre, L'Être et le Néant, p. 615.

${ }^{7}$ Ibidem.

${ }^{8}$ Ibidem, p. 629.

${ }^{9}$ Ibidem, p. 616. 
abierta' o el 'tragaluz'10 abierto sobre lo absoluto que permite un contacto directo con lo absoluto no humano. El filósofo francés rechaza esta primera concepción, por el motivo de que la muerte revela únicamente lo humano, desde el ángulo de lo humano: lo no humano se nos escapa plenamente. A pesar de su oposición a la trascendencia absoluta de la muerte con relación a la vida, Sartre sostiene, sin embargo, que la muerte no existe para lo viviente: para hacerlo, se remite, como veremos, a la 'situación-límite' y a su ontología de la libertad. Su posición se acerca, en cierta medida, al 'nada de la muerte' epicúreo, de acuerdo con el cual es imposible experimentar, en tanto que muerto, mi propio ser muerto. ${ }^{11}$ En ningún momento la muerte toca al para-sí. Éste no se la encuentra, a pesar de estar en condiciones de constatar sus consecuencias desde el exterior, por intermedio de la muerte del prójimo.

A partir del siglo XIX, surge una tanatología que inscribe a la muerte en la vida, como reacción contra una concepción realista de la muerte. Esta inserción o 'encarnación' de la muerte en el corazón de la vida se coloca en primer lugar en un nivel biológico (Klages, Scheler, Eucken, Simmel) antes de situarse en un plano ontológico; su representante por excelencia es Heidegger. Sartre se detiene largamente en esta segunda concepción de la muerte, que denomina idealista, de acuerdo con la cual la muerte forma el término último de una serie de fenómenos: dicho de otro modo, pertenece a esa serie y llega hasta otorgarle, según nuestro filósofo, su significación. La muerte, comparable con un acorde final de resolución al término de una melodía, sería inmanente a la existencia del Dasein humano. Esta 'recuperación' y, podríamos agregar, esta domesticación de la muerte tiene como meta, anota Sartre, no solamente interiorizar a la muerte, sino también, y sobre todo, 'humanizar' lo que describe como lo inhumano por excelencia, que es la muerte. "Ya no hay otro lado de la vida, y la muerte es un fenómeno humano, es el fenómeno último de la vida, vida todavía."12 La muerte forma "el

\footnotetext{
${ }^{10}$ Ibidem, p. 615, 617.

${ }^{11}$ Ver Bernard N. Schumacher, op. cit.

${ }^{12}$ Ibidem, p. 616.
} 
sentido de la vida'13 al influenciar retrospectivamente a la vida entera del sujeto-conciencia, del mismo modo que, por analogía, el acorde de resolución de una melodía constituye el sentido de ésta. Dicha humanización de la muerte implica también la 'yoidad' ['mienneté'] (la Jemeinigkeit heideggeriana) de la muerte, que, al convertirse en un fenómeno de mi vida personal, la vuelve única.

Sartre se fija como objetivo refutar 'rigurosamente' ${ }^{14}$ esta recuperación de la muerte, cuya paternidad le otorga a Rilke, a Malraux y sobre todo a Heidegger, omitiendo nombrar a sus precursores, como Scheler y Simmel. ${ }^{15}$ El filósofo francés concibe a la muerte como la anti-utopía, el anti-proyecto y el enemigo por excelencia que despoja a la vida del para sí de toda significación, y pone al descubierto el absurdo de toda espera, porque los problemas del sujeto "no reciben ninguna solución y porque la significación misma de los problemas permanece indeterminada". ${ }^{16}$ Sin detenerse en discutir las posiciones del poeta alemán y del novelista francés, Sartre concentra su crítica sobre la tesis del ser-hacia-la-muerte heideggeriano y la describe, en unas cuantas frases cortas, como una tentativa de recuperar la libertad del Dasein a pesar del límite aparente que la muerte le impone. Al analizar la concepción heideggeriana de la 'libertad para morir' ${ }^{17}$ y de la muerte como 'mi posibilidad más propia' -tesis que implica la interiorización de la muerte- la interpreta como un 'pase de magia' 18

${ }^{13}$ Ibidem.

${ }^{14}$ Ibidem, p. 617.

${ }^{15}$ Ver Rainer Maria Rilke, Le Livre de la Pauvreté et de la Mort, 1941, Lausanne, Bonnard, trad. del alemán al francés por A. Adamov y M. Geringer. [En español: Rainer María Rilke, El libro de las horas, Madrid, Hiperón, Libro tercero.] S. Gaulupeau, "André Malraux et la Mort" ["André Malraux y la Muerte"], Archives des Lettres Modernes, 1969, nr. 98. Max Scheler, Mort et survie [Muerte y sobrevivencia], 1952, París, Aubier Montaigne, trad. del alemán al francés por M. Dupuy. Georg Simmel, Lebensanschauung. Vier metaphysische Kapitel, 1918, München, Leipzig y "Métaphysique de la mort" ["Metafísica de la muerte"], idem, La tragédie de la culture et autres essais [La tragedia de la cultura y otros ensayos], 1988, París, Editions Rivages, trad. del alemán al francés por S. Cornille y Ph. Ivernel, p. 167-76.

${ }^{16}$ Jean-Paul Sartre, L'Être et le Néant, p. 624.

${ }^{17}$ Ibidem, p. 616.

${ }^{18}$ Ibidem, p. 617. En su obra póstuma, Cahiers pour une morale [Cuadernos para una moral], 1983, París, Gallimard, Sartre parece darle más positividad a esta definición 
que metamorfosea a la muerte en una 'muerte esperada', ${ }^{19}$ que constituiría el sentido de la vida del Dasein humano. La crítica sartriana se focaliza principalmente sobre una doble objeción: por una parte, es imposible que la muerte pueda ser esperada (contrariamente a la posibilidad real de esperar una muerte particular); por otra, es imposible que la muerte le otorgue un sentido a la existencia del para-sí.

\section{La espera de mi muerte}

Sartre hace notar antes que nada, y en mi opinión con razón, que es imposible fundar la ipseidad propia e irremplazable del Dasein humano, el 'solipsismo' existencial, sobre el sum moribundum, el 'soy/estoy moribundo' o el moribundus, el 'destinado a morir' (distinto del morir óntico). Heidegger opera, en efecto, un volteamiento del cogito sum cartesiano, al cual describe como una apariencia, y plantea, en Prolegomena zur Geschichte des Zeitbegriffes, que 'mi muerte' es fundadora de certidumbres. ${ }^{20} \mathrm{El}$ ser humano es 'su muerte' por el hecho mismo de ser un ser humano, es decir que es 'mi muerte' lo que me permite afirmar el ergo sum. El 'poder-morir' en cada instante de su existencia constituye la estructura propia del Dasein, el fundamento de su ser, su ipseidad. Precede al sum y le da sentido. El Dasein humano no puede ser otro que un ser-hacia-la-muerte. Heidegger comienza, según Sartre, por individualizar a la muerte humana, sosteniendo que la muerte es "lo único que nadie puede hacer por mí". ${ }^{21}$ Nadie está en condiciones de descargar a otro de su muerte. Sartre califica esta afirmación

heideggeriana de la muerte: "Pero es además mi muerte como posibilidad de no tener ya posibilidad, posibilidad de imposibilidad, alteridad en mi proyecto en el corazón mismo de ese proyecto [...] la relación con la muerte sólo existe como posibilidad de la muerte de cierto existente, y como el existente se define por sus proyectos, posibilidad de la imposibilidad de ciertos proyectos," p. 423.

${ }^{19}$ Jean-Paul Sartre, L'Être et le Néant, p. 617.

${ }^{20}$ Ver Martin Heidegger, Prolegomena zur Geschichte des Zeitbegriffes en Gesamtausgabe, Frankfurt am Main, Klostermann, 1979, t. 20, p. 437-8.

${ }^{21}$ Jean-Paul Sartre, L'Être et le Néant, p. 617-8. 
heideggeriana de 'gratuita' y la asimila a una 'mala fe evidente dentro del razonamiento'. La muerte no representa lo 'único' que nadie es apto para hacer por mí. Existen otras posibilidades - como amar, hacer un juramento, etc.- que sólo mi subjetividad está en condiciones de proyectar. Si examinamos los actos humanos desde el punto de vista de su utilidad, de su función, de su eficiencia o de su resultado, precisa Sartre, vemos que otro muy bien puede tomar mi lugar y realizar 'mis' posibilidades: cualquiera es capaz de morir en mi lugar o de morir por la patria o de amar a tal persona.

Al referirse al solipsismo existencial de la muerte, Heidegger individualiza el Dasein humano: dicho de otro modo, anota Sartre, "al proyectarse libremente hacia su posibilidad última, el Dasein accederá a la existencia auténtica [...] para alcanzar la unicidad irremplazable de la persona". ${ }^{22}$ Sartre le reprocha a la argumentación del filósofo de Freiburg su carácter circular. En efecto, ¿cómo probar semejante individuación de la muerte? ¿La muerte que me tocará un buen día es verdaderamente mi muerte? Sartre se opone al solipsismo existencial de Heidegger sosteniendo que no hay

ninguna virtud personalizante que sea particular a mi muerte. Muy por el contrario, sólo se convierte en mi muerte si me coloco ya desde la perspectiva de la subjetividad; es mi subjetividad, definida por el Cogito prerreflexivo, la que hace de mi muerte un irremplazable subjetivo y no la muerte la que daría la ipseidad irremplazable a mi para-sí. En ese caso la muerte no podría caracterizarse porque es muerte como mi muerte y, por consiguiente, su estructura esencial de muerte no es suficiente para hacer de ella ese acontecimiento personalizado y calificado que uno puede esperar. ${ }^{23}$

La crítica sartriana que concierne al intento heideggeriano de fundar la ipseidad en el sum moribundum es ciertamente pertinente, pero omite atraer la atención sobre el fundamento a priori que

${ }^{22}$ Ibidem, p. 617.

${ }^{23}$ Ibidem, p. 618-9. 
subtiende al ser-hacia-la-muerte. En efecto, la constitución del Dasein como un ser esencialmente adelantado-a-sí no implica lógicamente que sea un ser-hacia-el-fin, un ser mortal; supone solamente que es un ser radicalmente abierto hacia el por-venir de los posibles, hacia lo indeterminado. Desde un punto de vista ontológico, nada permite concluir que la tensión del por-venir implique un fin. Éste no está contenido ontológicamente en el no-ser-todavía, ni en el ser-adelantado-a-sí. En otros términos, no se puede conocer la condición de ser-hacia-lamuerte remitiéndose únicamente al ser posible tendido hacia el futuro. Sartre rechaza pensar a la muerte en el marco de una ontología de la finitud radical, planteada a priori, de la temporalidad. Desarrolla una ontología de la apertura radical del para-sí libre, donde la muerte no está incluida ontológicamente en la tensión libre del para-sí hacia el por-venir. La muerte proviene del exterior de la subjetividad. La estructura ontológica de la finitud no revela la condición de ser-haciala-muerte del para-sí, 'determina' únicamente su libertad, que, a pesar de ser absoluta en sí, se vuelve limitada cuando ejerce su actividad. La irreversibilidad que caracteriza al acto de la libertad del para-sí se debe a su contingencia y a su temporalización. "Por ser temporalmente indefinida, es decir, sin límites, su 'vida' no será menos finita en su ser mismo porque se vuelve único. La muerte no tiene nada que ver en eso; sobreviene 'entretanto', y la realidad-humana, al revelarse su propia finitud, no descubre por ello su mortalidad." 24 En suma, la finitud del para-sí no es fundada, según Sartre, por la muerte, sino por el acto de la libertad. Incluso si el para-sí fuera inmortal, sería finito. La muerte constituye un simple hecho contingente que proviene del exterior de la estructura del para-sí finito, es decir, que el descubrimiento de su propia finitud no implica por ello su condición de ser-hacia-la-muerte. Sólo 'la experiencia' de la muerte del otro me permite descubrir mi 'propiamente morir', cuando me vuelvo responsable de la significación de la existencia del otro muerto.

${ }^{24}$ Ibidem, p. 631. 
Sartre prosigue su crítica del ser-hacia-la-muerte heideggeriano focalizando su atención sobre la problemática de la espera de 'mi muerte'. Para hacerlo, distingue dos maneras de esperar: esperarse a la muerte no significa esperar la muerte.* Para que esta diferencia se vuelva más tangible, toma como ejemplo la espera que precede a la llegada de un tren en la estación. Espero en una estación de París la llegada de Pierre en el tren de Chartres, tomando en consideración la posibilidad de que factores exteriores puedan actuar sobre ese determinismo mecánico y retrasar o detener al tren. Estos diversos factores que hacen que el tren entre en la estación de París con más o menos retraso se pierden en la indeterminación, es decir, son imprevisibles. Estoy en condiciones de esperar a Pierre y, al mismo tiempo, esperarme a que ese tren venga con retraso. Ocurre lo mismo en lo que concierne a 'mi muerte'.

El objeto de la espera es un acontecimiento determinado que diversos procesos -también determinados- realizan y cuya actualización es previsible. Ocurre lo mismo con la condición de mortal del para-sí. Éste es, desde un punto de vista biológico, un sistema relativamente cerrado y aislado. A partir de esto, soy apto para esperar 'mi muerte' -la muerte natural que 'se actualiza' al término natural del proceso biológico del para-sí, en el sentido de que soy sustancialmente un mortal: 'mi muerte' por venir es un hecho cierto- mors certa.

'La actualización' de 'mi muerte concreta', la llegada del 'momento' de 'mi muerte', escapa de una determinación por deberse, según Sartre, a un hecho del azar que resulta de procesos biológicos y de factores exteriores. Dado que 'mi muerte' puede surgir en cualquier instante, a partir de mi proyección en lo mundano -hora incerta-, soy incapaz de esperar mi muerte. Sólo puedo esperármela.

La expresión 'esperar' mi muerte se aplica a esta conciencia de la necesidad de deber morir un día, mientras que 'esperarme a' mi muerte

* En francés es muy clara la diferencia entre attendre y s'attendre. Attendre significa esperar en el sentido de la espera de algo concreto (esperar el tren, en el ejemplo de Sartre). S'attendre da la idea de anticipación de que algo pueda ocurrir, aunque no es seguro que así sea (algo que retrase al tren, en el mismo ejemplo). [N. de T.] 
se refiere al poder morir de un instante al otro. No hay, anota Sartre, más que una diferencia de calidad entre los dos tipos de muerte expresada por las dos actitudes con respecto a la vida: esperar la muerte llamada 'natural' significa aceptar la empresa limitada de la vida; esperar la muerte llamada 'accidental' o 'precipitada' (accidente, enfermedad, etc.) equivale a aceptar que la vida es una empresa fallida. ${ }^{25}$

Dado que la muerte, según Sartre, acecha al para-sí en todo momento y puede surgir constantemente antes de que el para-sí haya terminado o realizado su tarea (que no haya realizado sus posibles), concluye que sólo estamos en posición de esperar una muerte natural si damos pruebas de enceguecimiento y de mala fe. Toda muerte nos 'cae' encima al azar de nuestra existencia. La muerte es siempre del orden de la indeterminación, y esto mismo ocurre en la que parece la más natural, como la última nota de una melodía. La componente del azar que 'decide' el momento preciso de 'la actualización' de la muerte, incluso la 'natural', le quita a ésta todo atributo de fin armonioso:

Esta perpetua aparición del azar en el seno de mis proyectos no puede captarse como mi posibilidad, sino, por el contrario, como la nadización de todas mis posibilidades, nadización que a su vez no forma ya parte de mis posibilidades. Así, la muerte no es mi posibilidad de ya no realizar presencia en el mundo, sino una nadización siempre posible de mis posibles, que está fuera de mis posibilidades. ${ }^{26}$

'Así es que yo no podría esperarla', concluye Sartre unas cuantas páginas más adelante, "es decir, echarme hacia ella como hacia una de mis posibilidades. Ella no podría por lo tanto pertenecer a la estructura ontológica del para-sí". ${ }^{27}$

${ }^{25}$ Ibidem, p. 620. Si no existiera una muerte llamada 'accidental', es decir, ninguna muerte que sobreviniera antes del límite biológico del individuo, sería completamente correcto sostener que espero mi muerte, como también que la vida no es una empresa fallida. La realidad cotidiana nos enseña, sin embargo, que la muerte natural sólo sobreviene muy pocas veces, y que no difiere desde un punto de vista biológico (en cuanto a sus causas y a sus factores) de la muerte llamada 'accidental'.

${ }^{26}$ Ibidem, p. 621.

${ }^{27}$ Ibidem, p. 629. 
Muy seguramente Heidegger hubiera aprobado con Sartre la distinción entre esperar 'mi muerte' y esperarme a 'mi muerte', en el sentido en que el filósofo francés lo entiende. Me parece que nos enfrentamos, en este contexto, a una incomprensión por parte de Sartre: no entendió el ser-hacia-la-muerte heideggeriano como la posibilidad de la imposibilidad y, más específicamente, el uso del término 'esperar mi muerte'.

En efecto, en primer lugar, Heidegger no se opone explícitamente a la comprensión de la muerte como la nadización de los múltiples proyectos y de las posibilidades ónticas del Dasein humano (la muerte no es idéntica a su cumplimiento $y$, por el contrario, viene muy frecuentemente a sorprenderlo y a quitarle futuros posibles). Ciertamente, ella es su posibilidad (ontológica) más extrema e íntima. La muerte forma parte de la estructura ontológica de la naturaleza humana y expresa, al mismo tiempo, paradójicamente, la supresión de esta misma estructura y de los posibles. En segundo lugar, Heidegger no afirma, ni siquiera de manera implícita, que el Dasein espere la muerte: rechaza las actitudes de espera y de rumiar con respecto a la muerte, que la despojan de la categoría de posibilidad misma. La comprensión heideggeriana de la muerte como posibilidad ontológica no traduce su presencia física en el seno de la vida, sino que expresa un fin intrínseco al ser-adelantado-a-sí, a saber, que pertenece a la estructura misma del Dasein. Cuando Sartre dice que el ser-hacia-la-muerte heideggeriano pertenece a una concepción llamada idealista de la muerte -es decir, la muerte como 'un fenómeno humano', o 'el fenómeno último de la vida, vida todavía' $-{ }^{28}$ su descripción no resulta adecuada a la lectura de los párrafos de Ser y Tiempo.

${ }^{28}$ Ibidem, p. 616. 


\section{La muerte como victoria del otro}

Sartre no se contenta con denunciar la proposición tanatológica heideggeriana; desarrolla una manera original de concebir a la muerte humana al introducirla en su estructura ontológica del ser-para-el-otro y su ontología de la libertad, así como en su teoría de la significación.

El ser humano descrito en L'Être et le Néant es fundamentalmente libre con relación a todo fin, todo valor, toda determinación natural, toda hetero-determinación, sin importar cuál sea. La libertad misma plantea el valor y las reglas de sus actos. Dicha conciencia autónoma libre entra constantemente en relación con sus semejantes. Sartre analiza la relación entre los para-sí desde el ángulo de la mirada. Comienza con una puesta en escena anodina: "Estoy en un parque público. No lejos de mí, hay una extensión de césped y, en la orilla de este césped, unas sillas. Un hombre pasa cerca de las sillas. Veo a ese hombre, lo capto a la vez como un objeto y como un hombre." ${ }^{29} \mathrm{La}$ aparente calma se interrumpe bruscamente cuando la mirada del otro se posa sobre mí: ese otro para-sí me capta a su vez como fenómeno, me desposee de mí mismo, reduciéndome al estado de objeto, es decir de artefacto, de en-sí. Justamente semejante reducción va en contra de la determinación original del para-sí que "se determina a perpetuidad él mismo a no ser el en-sí. Esto significa que no se puede fundar él mismo más que a partir del en-sí y contra el en-sí". ${ }^{30}$ La alteridad se revela como una maldición que proyecta al sujeto mirado en medio de las cosas, y provoca por eso mismo su alienación, la desintegración de su universo, de sus valores. La aparición del otro en el mundo corresponde a una descentralización del para-sí original: su mirada me alcanza en mi ser, me revela mi esclavitud y, por ello mismo, mi vergüenza. El otro me objetiviza entonces antes de ser convertido, a su vez, en objeto para mí que intento 'recuperar' mi subjetividad, mi 'ser': porque mi ser sólo puede realizarse en la medida en que me

${ }^{29}$ Ibidem, p. 311 . Ver p. 300 s; p. 430 s; p. 478 s.

${ }^{30}$ Ibidem, p. 128. 
apropio de la libertad del otro, y la someto a mi libertad. El para-sí, que tiende hacia la imposible síntesis ideal del en-sí-para-sí, queda prisionero en el círculo de la mirada-mirador-mirado, de esta lucha de objetivación y de recuperación de su subjetividad. En esta áspera rivalidad que opone a los para-sí, no hay vencedor ni vencido. Este estado constituye la estructura permanente del ser-para-el-otro. No hay lugar para una recepción no objetivante de mi ser por el otro.

El tipo de relación sartriano entre los para-sí presentado en $L$ 'Etre et le Néant está marcado por una ontología intersubjetiva negativa que se caracteriza por un conflicto perpetuo. Desde la perspectiva sartriana, la mirada del otro representa un verdugo constante para el yo: "El infierno son los Otros." "31 La relación entre los para-sí no es la del respeto y el amor por el prójimo en su ser y en su individualidad, sino la de una guerra sin armisticio y sin vencedor. El ser-para-el-otro es una negación interna recíproca del otro. Incluso las actitudes de indiferencia y de odio hacia el otro, actitudes que consisten en construir mi subjetividad sobre el derrumbe de la del prójimo, no permiten la desaparición de esta reciprocidad ontológica con el otro. La indiferencia me recuerda la existencia del otro por un sentimiento perpetuo de falta y de malestar. El odio a su vez implica también un reconocimiento de la libertad del otro. ${ }^{32}$

${ }^{31}$ Jean-Paul Sartre, Huis clos, 1994, París, Gallimard, Folio, p. 42, 93. [En español: Jean-Paul Sartre, A puerta Cerrada, 2004, Buenos Aires, Losada.] "Mi caída original es la existencia del otro", L'Être et le Néant, p. 321. "El pecado original es mi surgimiento en un mundo donde está el otro.” (p. 481). En los Cahiers pour une morale (p. 488), Sartre describe esta situación del infierno de manera muy precisa: “Cualquier esfuerzo del Para-sí para ser En-sí está por definición consagrado al fracaso. Así podemos dar cuenta universalmente del reino del Infierno, es decir, de esa región de existencia donde existir es usar todas las astucias para ser y es fracasar en el corazón de tales astucias y tener conciencia del fracaso. Es el mundo de la locura de que hablan Spinoza y los Estoicos."

${ }^{32}$ La intersubjetividad negativa desarrollada en L'Être et le Néant a partir de una ontología del para-sí-en-sí contiene ciertas debilidades que Sartre de manera expresa reconoció en sus escritos posteriores a L'Être et le Néant, y propuso una ligera modificación de su antropología. Plantea que el para-sí es en sí apto para quebrar, con la ayuda de una conversión cuyo exacto tenor no precisa, el infierno del círculo relacional entre las conciencias. Sostiene ciertamente, en la Critique de la raison dialectique, 1985, París, Gallimard, t. I, p. 193 s. [En español: Jean-Paul Sartre, Crítica de la razón dialéctica, Buenos Aires, Losada], una intersubjetividad 
Sartre introduce la muerte en el seno de esta estructura ontológica del ser-para-el-otro. Contrariamente a la tesis heideggeriana para la cual la muerte es un estado no relacional que rompe al ser-en-comunidad (Miteinandersein), el filósofo francés afirma que la muerte es esencialmente inseparable de la relación con el otro, y la concibe como la victoria definitiva, el triunfo del para-sí sobreviviente sobre el para-sí muerto que es así reducido a un en-sí, a una cosa desprovista de conciencia de sí. A su muerte, el para-sí cesa brutalmente de estar 'condicionado'. De repente, es proyectado en la incapacidad de encargarse y de darle un sentido a sus acciones pasadas o alterar su sentido. Su existencia, a partir de eso, queda fijada para siempre. Su conciencia

del sujeto-objeto, cuya situación original se caracteriza una vez más por el conflicto; dicha intersubjetividad hace que la primera actitud del individuo resida en la violencia que puede estallar en una guerra de potencia abierta. El peligro que cada uno constituye para cada uno reduce al otro a un ser humano inhumano o a una raza extranjera. Sartre traspone la ley de la integración recíproca entre los para-sí desarrollada en $L$ 'Être et le Néant al nivel de la relación entre los grupos. Cada grupo trata al otro grupo desde un punto de vista instrumental. Con vistas a suavizar su tesis del conflicto, nuestro autor introduce la dimensión del intercambio y del servicio recíproco, o de un trabajo con una meta común. Este tipo de relación intersubjetiva, más positiva que la que es desarrollada en L'Être et le Néant no implica, sin embargo, la consideración del prójimo como un fin en sí y un ser digno de respeto.

Sólo con la publicación de su obra póstuma, Cahiers pour une morale, Sartre introduce, tomando sus distancias con L'Être et le Néant, el respeto y el reconocimiento recíprocos de las libertades. Plantea la existencia de una actitud donde el sujeto llega hasta a regocijarse del otro sin buscar apropiarse de él. Así es el amor. "Yo amo si creo la finitud contingente del Otro como ser-en-medio-del-mundo, asumiendo mi propia finitud subjetiva y queriendo esa finitud subjetiva, y si, con el mismo movimiento que me lleva a asumir mi finitud-sujeto, asumo su finitud-objeto como la condición necesaria de la libre meta que ella proyecta y que se me presenta como fin incondicional." (Cahiers pour une morale, p. 516. Ver p. 430, 434, 523 s). Un tono similar está presente también en su entrevista-libro L'espoir maintenant [La esperanza ahora] (1991, París, Verdier), donde Sartre subraya que la presencia del prójimo y el yo-para-el-otro se vuelven prioritarias con relación al para-sí, es decir, que lo que yo hago es efectuado en relación con, y en conciencia del otro. Reconocemos aquí el concepto de conciencia moral. Sartre confiesa así: "[Yo había] dejado a cada individuo demasiado independiente en mi teoría del otro de L'Être et le Néant. [...] consideraba, a pesar de todo, que cada conciencia en ella misma, cada individuo en él mismo, era relativamente independiente del otro. No había determinado lo que intento determinar hoy: la dependencia de cada individuo con relación a todos los individuos." (p. 40). Ver Jean-Paul Sartre, "Interview with Jean-Paul Sartre”, Paul A. Schilpp (ed.) The Philosophy of Jean-Paul Sartre, 1981, La Salle, Open Court, p. 3-51, 13. 
de sí es abolida. Deslizándose por entero al pasado, se congela en un en-sí, sin que haya surgimiento de una nueva conciencia. El sentido de su vida y de sus acciones pasadas a partir de ello proviene de la buena voluntad, de la libertad del para-sí viviente. Éste decide libremente sobre su suerte, ya sea haciendo caer su existencia en el olvido de las masas o reconstituyendo su vida. El para-sí muerto -es decir, el ensí- sigue insertándose en la estructura ontológica fundamental de serpara-el-otro, pero está a merced del otro sobreviviente y puede sufrir cambios importantes desde el exterior sin ser responsable de ellos.

La muerte es el desenlace de la lucha que opone a las libertades de los para-sí, porque otorga la victoria al para-sí sobreviviente. La muerte representa en ese contexto preciso una 'alienación', 'un total desposeimiento' 33 de la persona del para-sí en beneficio del otro, desposeimiento que no solamente hay que comprender en el nivel de los bienes materiales, sino antes que nada en el nivel de la autodeterminación. Una vez muerto, el para-sí es 'presa de los vivientes'. ${ }^{34}$ Como está totalmente sometido a ellos, no está ya en condiciones de defenderse. Está condenado a no existir más que por el para-sí sobreviviente. Tal es el escándalo de la muerte, su absurdo. "Se presenta como la alienación permanente de mi ser-posible que ya no es mi posibilidad, sino la del otro." ${ }^{35}$

La afirmación del absurdo de la muerte se opone a Heidegger quien, según Sartre, sostiene que el ser-hacia-la-muerte otorga el sentido a la existencia humana. No me detengo aquí para subrayar la falsa interpretación sartriana sobre este tema, pues Heidegger excluye de su análisis ontológico la cuestión del sentido de la vida, como la del estatuto del mal de la muerte, que es competencia de un análisis óntico. El estudio ontológico del ser-hacia-la-muerte heideggeriano no incluye ningún juicio sobre un eventual absurdo de la muerte, incluso de la vida. ${ }^{36} \mathrm{La}$

${ }^{33}$ Jean-Paul Sartre, L'Être et le Néant, p. 628.

${ }^{34}$ Ibidem.

${ }^{35}$ Ibidem, p. 631-2.

${ }^{36}$ Ver Martin Heidegger, Etre et Temps, 1986, París, Gallimard, trad. del alemán al francés por F. Vezin, p. 300 s. [Sein und Zeit, 1976, Tübingen, Max Niemeyer, p. 246 s. En español: 
crítica sartriana con respecto a Heidegger reposa sobre la teoría de la significación que el filósofo francés pone en relación con su presentación del para-sí y la amenaza del prójimo. ${ }^{37}$

¿Qué implica esta teoría para la aprehensión de la muerte? Estipula que el pasado extrae su sentido del presente y el presente lo extrae del sentido del futuro. El por-venir procura la significación a la acción libre, presente y pasada, del para-sí. Él es, a partir de esto, 'por venir de sí mismo'. 'Ser sí, es venir a sí', ${ }^{39}$ tal es la estructura de la ipseidad. El fin aclara lo que es o, inversamente, las acciones pasadas y presentes reciben su sentido de las acciones futuras. Aquéllas acciones están continuamente condicionadas, en espera de la significación que éstas les confiarán. "Lo que es no adquiere entonces su sentido más que cuando está superado hacia el porvenir."40 El sentido de una acción libre del para-sí no es dada por el otro", ${ }^{41}$ ni por naturaleza, sino por el para-sí mismo que escoge libremente y solo la significación que quiere atribuirle a su pasado. De manera similar, su acción futura libre

Martín Heidegger, Ser y tiempo, 2003, Madrid, Trotta.] En el contexto de la reflexión sartriana sobre el vínculo necesario entre la muerte y la libertad, podríamos preguntarnos si una vida inmortal o infinita, que no dejaría, según Sartre, lugar para la libertad, para las elecciones posibles, no sería absurda y aburrida y no disminuiría el valor de la vida presente.

${ }^{37}$ No es inútil precisar que la teoría de la significación sartriana no se limita a la significación que el para-sí le da libremente a sus acciones - nivel de mi discurso-, sino que implica también dimensiones que escapan del otorgamiento de significación del para-sí y que le son, de alguna manera, impuestas desde el exterior de su subjetividad. Sartre subraya que nos encontramos "inmersos en un mundo cuyos complejos-utensilios pueden tener una significación que mi libre proyecto no les dio primero. Y en medio de ese mundo provisto ya de sentido, enfrentar una significación que es mía y que yo no me he dado tampoco, que me descubro como 'poseyendo ya'. [...] tres capas de realidad que entran en juego para constituir mi situación concreta: los utensilios ya significantes (la estación [...]), la significación que yo descubro como ya mía (mi nacionalidad [...]), y finalmente el Otro como centro de referencia al cual remiten esas significaciones. Todo sería muy simple, en efecto, si yo perteneciera a un mundo cuyas significaciones se descubrieran simplemente a la luz de mis fines propios". Jean-Paul Sartre, L'Être et le Néant, p. 591-2.

${ }^{38}$ Ibidem, p. 621.

${ }^{39}$ Ibidem, p. 622.

${ }^{40}$ Ibidem, p. 578.

${ }^{41}$ Sartre precisa ciertamente que el prójimo es apto para dar un sentido a mi pasado, e incluso, para redefinir a una persona dentro de una actitud de mala fe. 
determinará el sentido de su presente. La actual conducta libre de un para-sí en el presente paradójicamente se le aparece al mismo tiempo plenamente conciente y traslúcida (cogito prerreflexivo), y totalmente enmascarada por una libre determinación que él debe esperar todavía hasta que su por-venir le confíe un sentido a su acción presente. El para-sí es, a partir de esto, esencialmente espera, que se expresa por una serie "de espera de esperas que esperan a su vez esperas". ${ }^{42}$ Estas esperas tienden hacia un reposo último, que es imposible, donde todos los problemas recibirían una solución: la plenitud del en-sí-para-sí que le otorgaría una retoma total de la vida pasada y fijaría para siempre la curva de la existencia.

Mientras el para-sí está vivo, está en condiciones de cambiar la significación de sus acciones pasadas libres, y de 'repetir su tiro' continuamente. La entrada en escena de la muerte, que se debe al azar y que escapa de la libertad del para-sí, paraliza definitivamente en un presente inmutable la proyección de la libertad del para-sí hacia el porvenir. El para-sí muerto no es capaz ya de otorgar retrospectivamente una significación a sus acciones que pertenecen, a partir de eso, a los sobrevivientes. La muerte reviste entonces, para Sartre, el hábito del absurdo, pues no solamente destruye todo proyecto y contradice a la aspiración fundamental del para-sí de convertirse en un ser en-sípara-sí, sino que también, y ante todo, le quita al para-sí muerto la aptitud para dar un sentido - que proviene del futuro- a sus acciones libres pasadas. El absurdo de la muerte no reside prioritariamente en el retorno a la nada del para-sí, o en la supresión de su autoconciencia sino, ante todo, en la alienación de su ser-posible: está a merced del otro-sobreviviente que decide sobre el sentido que se le puede dar a la vida del difunto y a sus acciones pasadas. El absurdo de la muerte, como también de la vida, reside en la no realización de la espera, ${ }^{43}$ en la indeterminación de los problemas:

${ }^{42}$ Ibidem, p. 622.

43 "Si soy espera de esperas de espera y si, de golpe, el objeto de mi espera última y el que espera son suprimidos, la espera recibe de ello retrospectivamente el carácter de absurdo." Ibidem, p. 623. 
La muerte no es nunca lo que da su sentido a la vida: es, por el contrario, lo que le quita por principio toda significación. Si debemos morir, nuestra vida no tiene sentido porque sus problemas no reciben ninguna solución y porque la significación misma de los problemas permanece indeterminada. ${ }^{44}$

Ciertamente se debe mencionar de igual manera que Sartre propone otra razón del absurdo de la muerte: usa el concepto de absurdo para caracterizar la facticidad por contraste con la libertad. La vida y la muerte son absurdas, pues en tanto que condenado a ser libre, estoy constreñido al nacimiento y a la muerte, es decir, que no escogí nacer ni ser un ser mortal. La muerte es "un hecho contingente que, en tanto que tal, se me escapa por principio y resalta originalmente a mi facticidad". ${ }^{45}$ Unas cuantas páginas más adelante, Sartre escribe: "Yo soy un libre mortal". ${ }^{46}$

La teoría de la significación con relación al para-sí libre reposa, a fin de cuentas, sobre la célebre tesis sartriana según la cual la existencia precede a la esencia. Si ésta última no es un dato presente, sino que se hace en la libre proyección en el por-venir -el para-sí se fabrica a su gusto-, es correcto sostener que la muerte deja "en lo indeterminado la realización de los fines que me anuncian lo que yo soy". ${ }^{47}$ Yo sostengo, sin detenerme en ello, pues es algo que se ha debatido ampliamente, que la esencia del para-sí es un dato que escapa de la libertad del sujeto-conciente, es decir, que antecede a la existencia. Lo que yo soy desde el punto de vista de mi esencia -y no lo que yo podría ser en cuanto a mi realización, desarrollando mis múltiples capacidades y posibilidades- no depende del futuro: lo soy a partir de mi proyección

${ }^{44}$ Ibidem, p. 624. Precisa que "sería vano recurrir al suicidio para escapar de esa necesidad. El suicidio no podría ser considerado como un fin de vida del cual yo sería el propio fundamento. Al ser acto de mi vida, en efecto, requiere a su vez de una significación que sólo el porvenir le puede dar; pero como es el último acto de mi vida, se niega ese porvenir; así, se queda totalmente indeterminado".

${ }^{45}$ Ibidem, p. 630.

${ }^{46}$ Ibidem, p. 632.

${ }^{47}$ Ibidem, p. 629. 
en lo mundano. Además, un acontecimiento o una acción, según yo, es apta para recibir un sentido, no solamente de manera retroactiva, insertándose en un conjunto más amplio, como por ejemplo la vida personal, la historia, los valores o la fe, sino también en la presenteidad misma de su actualización y en la intencionalidad de la conciencia actuante. Ciertamente, es correcto decir que la muerte deja en la indeterminación la realización de los fines y de los proyectos, pero dichos fines no anuncian lo que yo soy. Más bien significan lo que yo podría ser bajo el aspecto de la realización de mis posibles. Soy lo que soy, desde el punto de vista de mi esencia, ya en el momento mismo en que me proyecto en el futuro.

Sartre concibe a la muerte como un enemigo, pues interrumpe la proyección de los posibles del para-sí; la muerte puede ser percibida, como lo subrayaron numerosos filósofos analíticos, como un mal en el sentido de la privación de los posibles. ${ }^{48}$ El filósofo francés, sin embargo, emprende un salto en su argumentación cuando vincula esta ruptura de la proyección de mis posibles al absurdo de toda mi vida. En efecto, estoy en condiciones de elaborar y de dar un sentido a numerosas acciones de mi vida, incluso si debo morir a fin de cuentas, lo que implica la no realización de una multitud de mis posibilidades. El retorno a la nada no le quita en sí el sentido a mis acciones pasadas. En cambio, puede, como lo sostiene Sartre, volver absurda la tensión ontológica hacia el 'ser', hacia la unión para-sí-en-sí, o, en otros términos, hacia la felicidad plena y la culminación del ser mismo de la persona.

La exigencia sartriana de un 'después' con vistas a otorgarles un sentido a las acciones libres presentes y pasadas puede ser leída de dos maneras distintas, en el contexto de su percepción de la muerte como un absurdo. Por una parte, ésta tiene su origen en la incapacidad del para-sí muerto de dar un sentido a su vida pasada, por lo que el otorgamiento de sentido al para-sí difunto proviene a partir de la buena voluntad del otro-sobreviviente. Por otra parte, la muerte es absurda

\footnotetext{
${ }^{48}$ Ver Bernard N. Schumacher, op. cit.
} 
porque, al suprimir radicalmente la proyección de los posibles, vuelve inaccesible la realización de la tensión más profunda del para-sí, que no es otra que la unidad del para-sí-en-sí. La muerte elimina en definitiva el núcleo mismo del para-sí, que es la libertad autónoma, y reduce el para-sí a un en-sí. La posición sartriana parece implicar que la vida tendría un sentido si, por una parte, el para-sí continuara siendo post mortem, salvaguardando al mismo tiempo su identidad personal y buscando proyectarse libremente hacia el por-venir -lo que supondría también una resurrección del cuerpo para que el parasí pueda continuar siendo-en-situación-o si, por otra parte, el para-sí consiguiera alcanzar la identidad del para-sí-en-sí, que consiste en la totalidad del sentido. ${ }^{49}$ Pero como la muerte significa a priori la destrucción total del sujeto, que por definición la libertad requiere a la muerte, y que el para-sí-en-sí es irrealizable, la muerte revela, según Sartre, lo absurdo de la vida y la victoria de la libertad del otro sobre la del para-sí muerto.

\section{La muerte como una situación-límite}

Sartre se abre un camino entre la concepción idealista, que considera a la muerte como inmanente a la estructura biológica u ontológica del para-sí, y la concepción realista, que la ve como un estado exterritorial a la vida. Para hacerlo, transpone la problemática de la relación entre

${ }^{49}$ Sartre considera, en los Cahiers pour une morale (p. 339), la posibilidad de una vida temporal infinita donde el para-sí pudiera realizar todos sus posibles. Sartre describe indirectamente esta vida como absurda, pues en la medida en que el para-sí realizara todos sus posibles, el para-sí "desaparecería en tanto que individualidad y en tanto que libertad. Pero para que esa elección no tenga la pura gratuidad de la elección divina, su limitación no tiene que venirle de él mismo. No se trata de elegir sus límites a partir de una infinita posibilidad, sino de elegir dentro de los límites. Dichos límites están necesariamente dados. [...] Así, la elección de los posibles implica a la muerte, y la muerte como contingencia. Implica también que los posibles puedan siempre no ser realizados. [...] Ser libre es correr el riesgo perpetuo de ver que las empresas de uno fracasen, y que la muerte quiebre el proyecto. Hablar también de la finitud de la muerte. La libertad no se concibe fuera de la muerte". 
la vida y la muerte en el nivel de su ontología de la libertad. Hemos visto, en un primer tiempo, que la mirada del prójimo constituye un límite real a la libertad absoluta del para-sí, límite que no es propio de la libertad del para-sí, sino que es externa a su subjetividad. $\mathrm{Su}$ vana tentativa de arrogarse la libertad del otro se expresa por "lo irrealizable por realizar' que Sartre describe como "la exterioridad que permanece exterioridad incluso en y por la tentativa del para-sí por interiorizarla". ${ }^{50}$ Este irrealizable representa el límite exterritorial al para-sí, pero únicamente como límite de su libertad. Al elegirse libremente, la libertad del para-sí elige por sí misma sus límites. $\mathrm{Su}$ finitud es externa al para-sí. ${ }^{51}$

Del mismo modo que comprende a la libertad del prójimo como un límite de mi libertad, Sartre desplaza el parámetro de lectura sobre la noción de sentido, y describe a la muerte como una 'situación-límite' externa a la libertad del para-sí, como un puro 'hecho contingente'. ${ }^{2}$ Se trata de un 'dado' ${ }^{53}$ que proviene del exterior de la subjetividad del para-sí por el hecho mismo de que el otro existe. La muerte reside en el sentido futuro que mi para-sí actual tendrá para el otro: una vez muerto, como lo acabamos de ver, mi 'ser posible' escapa de mi posi-

${ }^{50}$ Jean-Paul Sartre, L'Être et le Néant, p. 613.

51 "La libertad retoma bajo su cuenta y hace entrar en la situación los límites irrealizables, eligiendo ser libertad limitada por la libertad del otro. Por consiguiente, los límites externos de la situación se vuelven situación-límite, es decir, que son incorporados a la situación desde el interior, con la característica 'irrealizable' como 'irrealizables por realizar', como reverso escogido y huidizo de mi elección, se vuelven un sentido de mi esfuerzo desesperado de ser a pesar de que estén situados a priori más allá de ese esfuerzo, exactamente como la muerte [...] se vuelve situación-límite a condición de que sea tomada como un acontecimiento de la vida, si es que indica hacia un mundo donde mi presencia y mi vida no se realizan ya, es decir, hacia un más allá de la vida. El hecho de que haya un más allá de la vida, en tanto que no toma su sentido más que por y dentro de mi vida, y que sin embargo permanece para mí irrealizable; el hecho de que haya una libertad más allá de mi libertad, una situación más allá de mi situación y por la cual lo que yo vivo como situación está dado como forma objetiva en medio del mundo: tales son dos tipos de situación-límite que tienen el carácter paradójico de limitar mi libertad por todas partes y sin embargo no tener otro sentido que el que les confiere mi libertad." Ibidem, p. 613-4.

\footnotetext{
52 Ibidem, p. 630.

${ }^{53}$ Ibidem, p. 631.
} 
bilidad y pertenece a partir de ese momento a la posibilidad del otro. La muerte es ciertamente externa al para-sí, es decir, que éste nunca está en condiciones de encontrarse con la muerte. Ésta no constituye la posibilidad del para-sí, como sostiene Heidegger, sino "la permanencia indefinida de su ser-para-el-otro". ${ }^{54}$ No existe para el para-sí viviente y escapa de su existencia directa. Sólo interviene entretanto y se revela como 'lo indescubrible'. ${ }^{5}$

En ese desplazamiento de la reflexión tanatológica al nivel de la ontología del para-sí, Sartre cambia la acepción comúnmente atribuida a los conceptos de mortal y de muerte: el primero representa "el ser presente que yo soy para el otro", y el segundo, "el sentido futuro de mi para-sí actual para el otro". ${ }^{56}$ La muerte limita no sólo los proyectos futuros del para-sí, sino también, y sobre todo, el sentido de sus acciones pasadas (del para-sí muerto) dejándolas a merced de la interpretación del otro-sobreviviente. Aunque la muerte no merme nunca al para-sí, y éste último no se encuentre nunca con su muerte en tanto que para-sí vivo, sin embargo está en condiciones de experimentarlo en el sentido de que lo habita en medio de cada uno de sus proyectos como su 'ineluctable reverso'.

La libertad que es mi libertad permanece total e infinita; no es que la muerte no la limite, sino que la libertad nunca se encuentra con ese límite, la muerte no es de ninguna manera un obstáculo para mis proyectos; es solamente un destino fuera de esos proyectos. No soy 'libre para morir', sino que soy un libre mortal. Como la muerte escapa de mis proyectos porque es irrealizable, yo mismo escapo de la muerte en mi proyecto mismo. ${ }^{57}$

${ }^{54}$ Ibidem, p. 632.

${ }^{55}$ Ibidem, p. 630.

${ }^{56}$ Ibidem, p. 632.

${ }^{57}$ Ibidem, p. 632. Sartre plantea en los Cahiers pour une morale (p. 338-9) el vínculo intrínseco entre la libertad y la muerte. 


\section{Conclusión}

Aunque sea necesario subrayar la pertinencia de algunos de los reproches que Sartre formula contra la posición propuesta por Heidegger, dudo que el conjunto de las críticas sartrianas sea 'irrefutable', como sostiene Jolivet. ${ }^{58}$ En efecto, varios de sus ataques contra el filósofo de Friburgo resultan ser inadecuados: aquéllos, por ejemplo, contra la presentación de la muerte como mi posibilidad y como el sentido de mi existencia, o las que formula contra la idea de la espera de mi muerte. La reflexión sartriana no se contenta, sin embargo, con una simple crítica del ser-hacia-la-muerte heideggeriano y de la presentación llamada realista. Propone concebir a la muerte de manera innovadora, dentro del contexto muy preciso de su ontología-antropología del ser-para-el-otro y de la libertad como fundamento del ser, al mismo tiempo que aborda la problemática del sentido de la vida y del absurdo de la muerte.

Antes de que Bloch hubiera emprendido la quebradura de la ontología de la finitud heideggeriana en su Principio Esperanza ${ }^{59}$ desarrollando una ontología de la apertura radical, Sartre rechaza, desde el punto de vista ontológico, la presenteidad del ser (a saber, el fin) en el no-ser-todavía. El fundamento de la finitud del para-sí sartriano no reside en la muerte, sino en la libertad, que, a pesar de ser absoluta, se vuelve limitada. La experiencia de la muerte del otro me empuja a ser responsable de la significación que tengo a bien darle a la existencia del para-sí muerto. La muerte no se revela por la angustia existencial heideggeriana, sino por la mediación de la libertad del otro y, de manera última, por la muerte del otro. Sartre no concibe a la muerte como mi

${ }^{58}$ Régis Jolivet, Le problème de la mort chez M. Heidegger et J.-P. Sartre [El problema de la muerte en M. Heidegger y J.-P. Sartre], 1950, Abbaye Saint Wandrille, Editions de Fontenelle, p. 44.

${ }^{59}$ Ver Ernst Bloch, Le Principe Espérance, París, Gallimard, trad. del alemán al francés por Fr. Wuilmart, p. 1976 s, 3 volúmenes [Das Prinzip Hoffnung dans Ernst Bloch Werkausgabe, Frankfurt am Main, Suhrkamp, 16 tomos, p. 1969 s, vol. v]. [En español: Ernst Bloch, El principio Esperanza, Madrid, Trotta.] 
posibilidad, sino como el fin de mis posibilidades para convertirse finalmente en la posibilidad del otro. La originalidad de su posición consiste en desplazar el parámetro de lectura: de mi muerte como lo que me separa de los otros, pasamos a mi muerte como intrínsecamente vinculada a mi relación con el otro, relación que está, sin embargo, profundamente impregnada por una lucha sin merced por la dominación total de la libertad del otro. La muerte es a partir de eso percibida dentro de este contexto particular como la culminación trágica del combate que libran los para-sí entre ellos desde su proyección en lo mundano. - Es interesante preguntarse en qué medida la muerte puede ser un mal para el para-sí muerto. ¿Hasta qué punto puede hacerle daño (dentro del contexto en donde el otro-sobreviviente otorga o niega un sentido a las acciones del para-sí muerto y decide sobre la suerte de éste último), si el muerto ya no es? Volvemos a encontrar el desafío de Epicuro, a saber, que la muerte no puede ser un mal, no puede causarme un daño, dado que cuando estoy muerto, ya no soy; igualmente, se podría objetar, en el caso del argumento de Sartre, que el otro no puede causarme daño cambiando el sentido de las acciones de mi vida, pues no estoy ya allí para sufrir por ello, para ser afectado por ello. - La reducción del para-sí muerto a un en-sí donde el sentido de sus acciones pasadas está irreversiblemente sometido a la libertad y a la buena voluntad del para-sí sobreviviente, la victoria total y sin apelación de éste último sobre el para-sí muerto expresa, para Sartre, el absurdo de la muerte. Ésta no reside así, principalmente, en el retorno a la nada del sujeto-conciencia, ni en la imposibilidad in se del para-sí muerto para proyectarse libremente hacia el por-venir, hacia futuros posibles, es decir, crear continuamente su esencia y darle una significación a sus acciones pasadas y presentes. El absurdo de la muerte, y agreguemos quizás su estatuto de mal, no residen, a partir de eso, más que secundariamente en esa reducción instantánea a la nada de los posibles y de los proyectos.

La tanatología sartriana reposa ante todo sobre su ontología de la libertad y sobre el concepto de la facticidad, así como sobre su tesis de la relación negativa entre los para-sí. Una vez que se ha puesto 
en duda ese fundamento, como lo hará el propio Sartre en sus obras posteriores a $L$ 'Etre et Le Néant, ${ }^{60}$ la concepción de la muerte dentro del marco de la relación con el otro debería ser corregida a su vez. No podríamos ya sostener el absurdo de la muerte, ni su estatuto de 'mal', a partir de la lucha sin merced que opone a los para-sí -aunque sea posible afirmar a uno y al otro situándose en el nivel de la facticidad y de la libertad-. Sería necesario sostener ese carácter absurdo y de 'mal' a partir del hecho de que la muerte priva al para-sí de la capacidad para proyectar sus posibles y sus proyectos, y que interrumpe - a veces de manera brutal- la tensión fundamental del 'para sí' para cumplir y realizar proyectos personales. Es el razonamiento que han hecho ciertos filósofos analíticos. Además, dentro del marco de una ontología que promoviera una intersubjetividad positiva donde el prójimo no sería ya percibido como un enemigo, sino como una ayuda indispensable para la realización plena del 'para sí' libre-y no solamente necesario para el descubrimiento del para-sí libre-; y donde el vínculo entre los para-sí se caracterizara por un mínimo de amistad o de amor; en ese contexto, entonces, la muerte del otro, y más particularmente la muerte de un ser querido, no podrían ya ser captadas como la victoria final de la sujeción sobre su libertad, sino más bien como la posibilidad, aunque dolorosa, para el sobreviviente de verse empujado hacia aguas profundas, de dejarse desestabilizar y de volver a cuestionarse. La muerte del otro, descrita por Jaspers como una 'situación-límite', ${ }^{61}$ podría revestir, a pesar de su cualidad negativa, cierto papel positivo al alentar al sobreviviente a descubrir su ser, su fundamento mismo: lo empujaría a trascender su contingencia y su facticidad y, a fin de cuentas, a vivir mejor.

${ }^{60}$ Pienso muy particularmente en los Cahiers pour une morale y en L'espoir maintenant.

${ }^{61}$ Ver Karl Jaspers, Philosophie. Orientation dans le monde. Eclairement de l'existence. Métaphysique [Filosofia. Orientación en el mundo. Iluminación de la existencia. Metafísica], 1986, París, Springer, trad. del alemán al francés por Jeanne Hersch, p. 436 s. [Philosophie, Berlin, Springer, 1932, p. 220 s.] 
La reproducción total o parcial de este artículo se podrá hacer si el ITAM otorga la autorización previamente por escrito. 